\title{
Securing Pet Food from Florida Black Bears and Coyotes ${ }^{1}$
}

\author{
Kelley C. Anderson and Elizabeth F. Pienaar ${ }^{2}$
}

\section{Food for Thought}

The Florida black bear and the coyote are both prevalent throughout the state of Florida. The Florida black bear, once a threatened species, is now thriving with an estimated population of over 4,000 bears. Although the number of coyotes in Florida is unknown, the range of the species within the state has been growing in recent years. With the human population expanding and increased development of natural lands, the potential for conflicts between people and these two species has risen.

The number one cause of human-wildlife conflict for these species are food attractants. Both bears and coyotes have an excellent sense of smell. These animals can live in human-dominated landscapes where they find easy sources of highly caloric food. Once a bear or coyote finds an easy food source, it is more likely to return to the area repeatedly and eventually lose its fear of humans. A "foodconditioned" animal can pose a threat to your pet's safety and is in danger of being shot, euthanized, or killed in an automobile collision.

\section{What's the law?}

- It is illegal to intentionally or unintentionally feed a black bear or coyote in Florida with food (including pet food) or garbage (see http://myfwc.com/news/resources/ fact-sheets/feeding-rules-and-penalties/).

- It is illegal to intentionally harm a black bear in Florida, with the exception of protecting a human life.

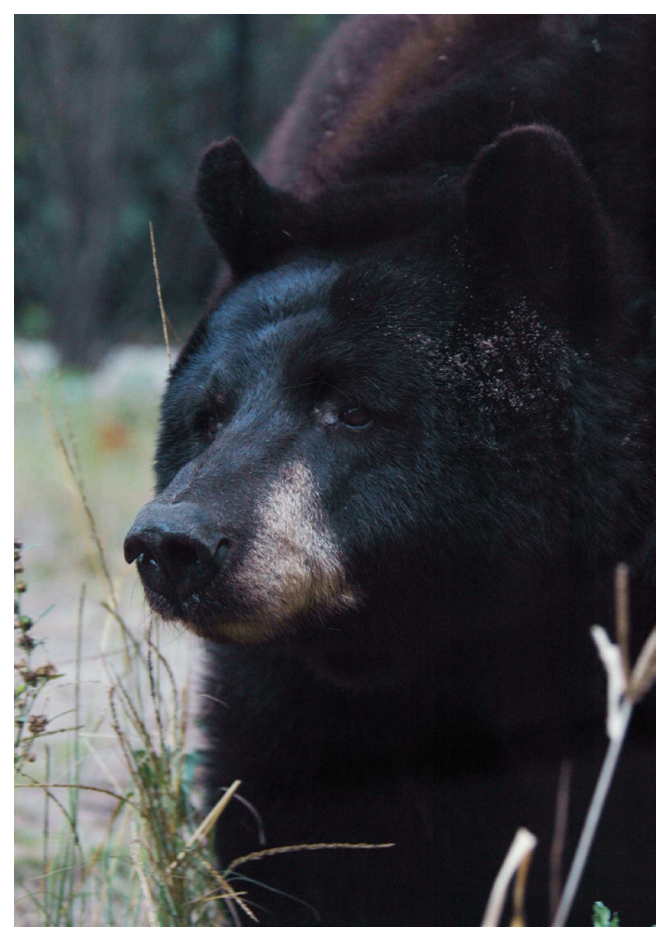

Figure 1. Bears will break into bags of pet food, even if the bags are sealed.

Credits: UF/IFAS

- You may humanely euthanize a coyote in accordance with the recommendations of the American Veterinary Medical Association. However, you may not kill a coyote on someone else's land without the landowner's permission, and you must be legally permitted to use and discharge a firearm before you shoot a coyote.

1. This document is WEC392, one of a series of the Wildlife Ecology and Conservation Department, UF/IFAS Extension. Original publication date December 2017. Visit the EDIS website at http://edis.ifas.ufl.edu.

2. Kelley C. Anderson, masters student, Department of Wildlife Ecology and Conservation; and Elizabeth F. Pienaar, assistant professor and Extension specialist - Human Dimensions of Wildlife, Department of Wildlife Ecology and Conservation; UF/IFAS Extension, Gainesville, FL 32611. 


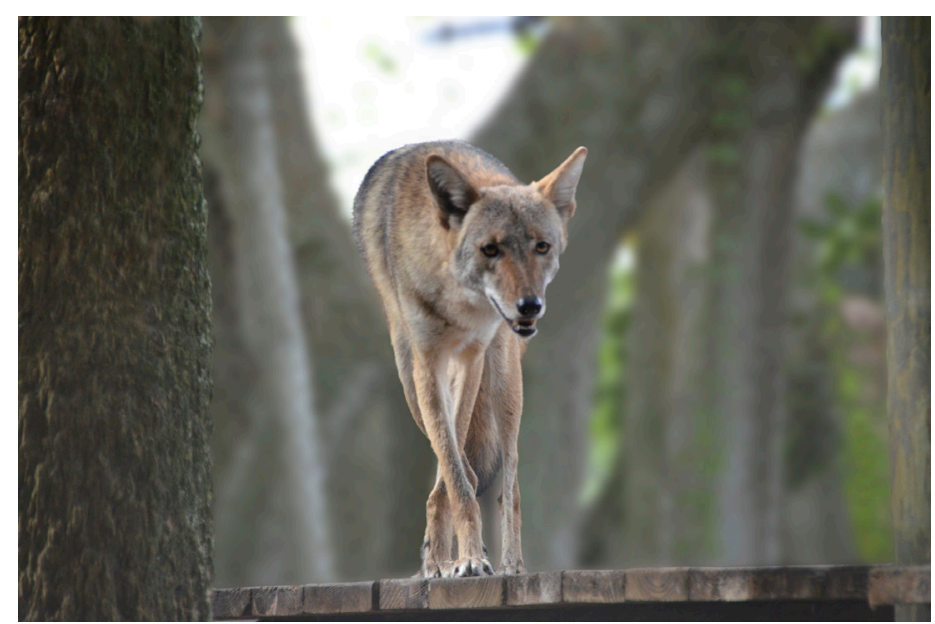

Figure 2. Coyote

Credits: Florida Fish and Wildlife Conservation Commission

\section{Protecting Your Pet's Food}

Compared to a coyote or a bear's natural diet, pet food is high in calories and has a pungent odor that attracts animals. The best way to secure your pet's food is by keeping it indoors. This can be your house or a secure area such as a shed or barn. It is also important to feed your pets indoors. Having pet food outdoors for any period of time has the potential to attract wild animals, including bears and coyotes. For your pet's safety, it is important to never leave your pet tethered by their food or unattended with no way to move a safe distance away from their food.

If possible, feed your pets indoors. If you must feed outdoors, remove any remaining food after your pet has finished its meal. Coyotes and bears are most active at night, dusk, and dawn. Avoid feeding your pets at these times.

\section{Outdoor Pens and Electric Fencing}

If you keep your pets in an outdoor pen, take precautions to avoid conflicts with bears or coyotes. Construct your pen of sturdy material such as fencing. (Window screen is not sturdy, and a screened area, such as a lanai, is not protected from coyotes or bears.) The pen must also have a roof and a skirt that extends outward underground to prevent digging. If possible, construct the pen away from areas with natural cover such as tall grasses or tree-lines. Electric fencing deters black bears, and pens surrounded by electric fences are more effective at preventing conflicts with both coyotes and bears.

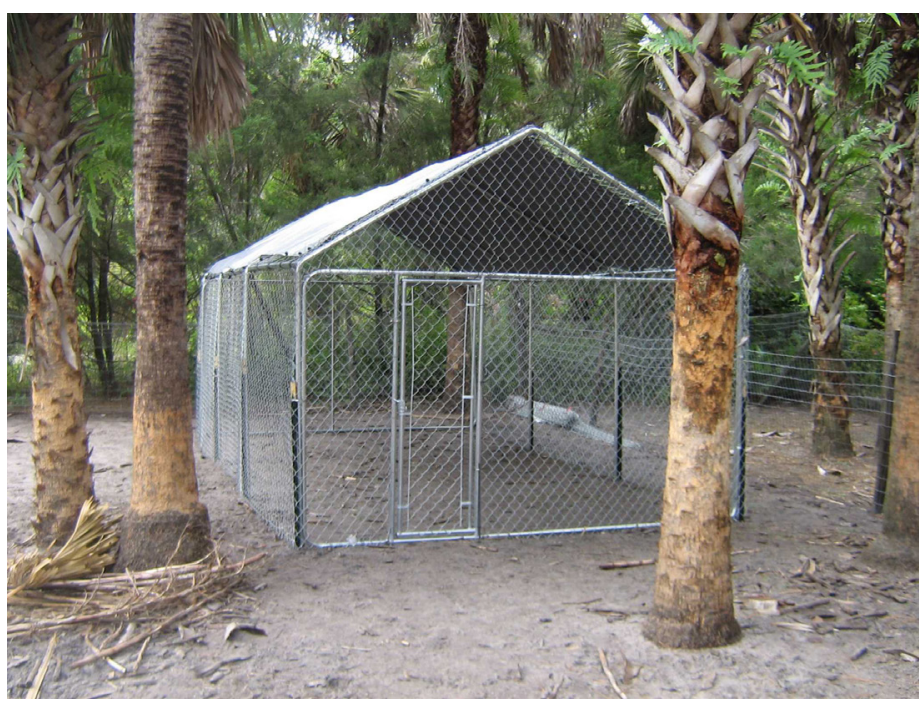

Figure 3. An example of a secure outdoor pen that will restrict wildlife from gaining access.

Credits: Mark Lotz

\section{More Information}

For more information on bears and coyotes in Florida, visit www.myfwc.com. Helpful links are listed below:

Living with the Florida black bear: http://myfwc.com/ wildlifehabitats/managed/bear/living/

Living with coyotes in Florida: http://myfwc.com/ conservation/you-conserve/wildlife/coyotes/

Protect your pets: http://myfwc.com/wildlifehabitats/ managed/bear/living/protect-pets/ 